\section{"CATCH 22" sans cardiac anomaly, thymic hypoplasia, cleft palate, and hypocalcaemia: cAtch 22. A common result of 22 q11 deficiency?}

The recent invited Editorial and outstanding series of articles in this Journal ${ }^{1-8}$ describe $22 \mathrm{q} 11$ deletion with the acronym "CATCH 22" (Cardiac anomaly, Abnormal facies, Thymic hypoplasia, Cleft palate, and Hypocalcaemia). Although the phenotypic variability was noted, it should be emphasised that many patients present with extremely mild symptoms and do not recapitulate the full spectrum alluded to by the "CATCH 22" acronym. Thus, the unifying feature appears to be the presence of a $22 \mathrm{q}$ microdeletion. Of a cohort of 150 presumed "CATCH 22" cases followed in Australia, only $35 \%$ have a significant cardiovascular anomaly and $25 \%$ overt or submucous cleft of the palate. Only 10 have the complete DiGeorge syndrome or a "full CATCH". To illustrate the milder range which constitutes the majority of the Australian patients, we wish to report a case of 22q11 deficiency that did not have Cardiac anomaly, Thymic hypoplasia, Cleft palate, or Hypocalcaemia.

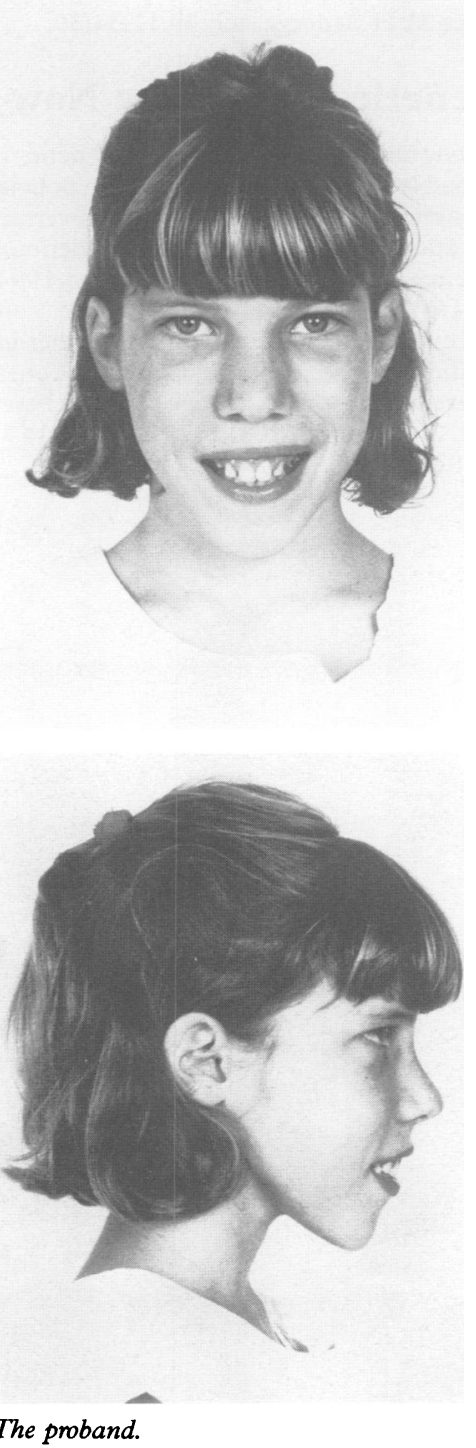

The proband was referred from a developmental assessment unit at the age of 11 because of hypernasal speech. Her parents are normal, white, and unrelated, and in their mid thirties. She has one sib, a female, two years older, who is normal. The pregnancy was uneventful and she was born at 37 weeks weighing $2340 \mathrm{~g}$ with a length of $48.8 \mathrm{~cm}$. Her early development was slightly slow but not outside normal limits. She smiled at 12 weeks, sat at 8 months, crawled at 10 months, and walked at 15 months. She started to join words together by about $2 \frac{1}{2}$ years of age. Ear infections started at 8 to 9 months. Glue ear was diagnosed and ventilating tubes were inserted for the first time at the age of 2 years. Feeding and swallowing have been unremarkable, though she occasionally regurgitated milk through the nose. An umbilical hernia was repaired at the age of $2 \frac{1}{2}$ years. She is in mainstream schooling, but has needed remedial teaching. Teachers report an enthusiastic and cooperative girl who is having great difficulty with mathematics and any subject which requires logic and reasoning. When tested on Stanford Binet IQ scale 4 th edition, she functioned in the borderline to low average range.

On examination, at 11 years of age, her height was between the 10th and 25 th centiles, weight between the 10 th and 25 th centiles, and head circumference between the 50th and 75th centiles. She had a "long" face deficient aleque, almond shaped palpebral fissures, dysplastic ears with inturned edges, and a small lower jaw (figure). There was no hypotonia. Serum calcium and parathyroid hormone were normal. Formal cardiac assessment and echo showed no abnormality, including the conotruncal region, such as right aortic arch. Immunological testing including $T$ cell subsets, Concanavalon $A$, and $T$ cell esterase were within normal limits. Her palate appeared short and she had hypernasal speech. Her speech was intelligible but the parents reported that often people ask her to repeat what she has said and her speech deteriorates when she is tired. Videofluoroscopy showed a good movement of the palate with a good knee to the palate; hearing was normal. Pharyngoplasty and palatal lengthening resulted in reduction of hypernasality and increased intelligibility.

High resolution chromosome analysis to the 700 band level was normal. FISH analysis was performed using a cosmid probe corresponding to locus D22S75 (N25) within the DiGeorge critical region. A distal marker, Cos82, was used as a control probe to identify the chromosome 22 homologues. A hybridisation signal was detected on only one of the chromosomes 22 in $15 / 15$ metaphases examined with marker N25. This finding is consistent with the presence of $22 \mathrm{q} 11$ deletion.

Although this patient may represent one end of a spectrum, the absence of overt or submucous cleft palate, overt or subclinical conotruncal congenital heart disease, hypoparathyroidism, or thymic deficiency was not unusual in our 22q11 deleted patients. For the patient we describe here, the thymus may have failed to descend completely, but it is clearly functional. ${ }^{9}$ Further, it is clear that the size of the deletion does not appear to determine or correlate with the severity of the anomalies. ${ }^{10}$ Thus, ascertainment of mild cases in parents and their offspring is important for proper genetic counselling, as intrafamilial variability is common. ${ }^{6}$ This is an important syndrome for the dysmorphologist to recognise ${ }^{11}$ and, though con- sciousness can be increased by the acronym "CATCH 22" it should not be rigidly adhered to in establishing a provisional diagnosis of 22q deletion.

$$
\begin{array}{r}
\text { ANTHONY LIPSON } \\
\text { Department of Genetics, } \\
\text { Children's Hospital, } \\
\text { Camperdown, Sydney, 2050, Australia. } \\
\text { BEVERLY EMANUEL } \\
\text { Division of Human Genetics and Molecular Biology, } \\
\text { The Children's Hospital of Philadelphia, } \\
\text { 34th Street and Civic Centre Boulevard, } \\
\text { Philadelphia, PA 19104, USA. } \\
\text { PETER COLLEY } \\
\text { KERRY FAGAN } \\
\text { Division of Molecular and Cell Biology, } \\
\text { fohn Hunter Hospital, } \\
\text { New Lambton, NSW 2305, Australia. } \\
\text { DEBORAH A DRISCOLL } \\
\text { Department of OB-GYN, } \\
\text { Hospital of the University of Pennsylvania and } \\
\text { The Children's Hospital of Philadelphia, } \\
\text { 34th Street and Civic Center Boulevand, } \\
\text { Philadelphia, PA 19104, USA. }
\end{array}
$$

1 Hall JG. CATCH 22. F Med Genet 1993;30: 801-2.

2 Burn J, Takao, A, Wilson D, et al. Conotruncal anomaly face syndrome is associated with a deletion within chromosome 22q11. $\mathcal{F} \mathrm{Med}$ Genet 1993;30:822-4.

3 Driscoll DA, Salvin J, Sellinger B, et al. Prevalence of 22q11 microdeletions in DiGeorge and velocardiofacial syndromes: implication for genetic counselling and prenatal diagnosis. 7 Med Genet 1993;30:813-17.

4 Goldmuntz E, Driscoll D, Budarf ML, et al. Microdeletions of chromosomal region 22q11 in patients with congenital conotruncal $22 \mathrm{q} 11$ in patients. $¥$ Med Genet 1993;30:807-12.

5 Greenberg F. DiGeorge syndrome: an historical review of clinical and cytogenetic features. $\mathcal{f}$ Med Genet 1993;30:803-6.

6 Holder SE, Winter RM, Kamath S, Scambler $P J$. Velocardiofacial syndrome in a mother and PJ. Velocardiofacial syndrome in a mother and daughter: variability of the clinic

7 Wadey R, Daw S, Wickremashinghe A, et al. Isolation of a new marker and conserved sequences close to the DiGeorge syndrome marker HP500 (D22S134). F Med Genet 1993; 30:818-21.

8 Wilson DI, Burn J, Scambler P, Goodship J. DiGeorge syndrome: part of CATCH 22. $\dot{f}$ Med Genet 1993;30:852-6.

9 Bale PM, Sotelo-Avila C. Maldescent of the thymus: 34 necropsy and 10 surgical cases, including ectopic thymus medial to the mandible. Pediatr Pathol 1993;13:181-90.

10 Motzkin B, Marion R, Goldberg R, Shprintzen $R$, Saenger P. Variable phenotypes in velocardiofacial syndrome with chromosomal decardiofacial syndrome with chrom

11 Lipson AH, Yuille D, Angel M, Thompson PG Vandervoord JG, Beckenham EJ. Velocardiofacial (Shprintzen) syndrome: an important syndrome for the dysmorphologist recognise. $\mathcal{F}$ Med Genet 1991;28:596-604.

\section{Skeletal malformations and polycystic kidney disease}

Dr Winter's comment ${ }^{1}$ on our paper describing an infant with autosomal dominant polycystic kidney disease (ADPKD) and skeletal malformations ${ }^{2}$ raises an interesting point as to the possible diagnostic framing of the complex polysyndactyly present in the patient. We are grateful for the opportunity to discuss this case further and to give more clinical and radiological details, as suggested.

Our patient had complete bilateral syndactyly of the hands associated with forced flexion and soft tissue fusion. Radiographs showed five metacarpals, hypoplastic 